\title{
EFFECT OF RADIAL IMPELLER SIZE IN THE PRESENCE AND ABSENCE OF BAFFLES ON THE COPPER EXCHANGE ON ZEOLITE NaX
}

\author{
Sandra Svilović ${ }^{*}$ - Marija Ćosić -Anita Bašić \\ ${ }^{1}$ Department of Chemical Engineering, Faculty of Chemistry and Technology, University of Split, Ruđera Boškovića 35 \\ Split, Croatia.
}

\begin{tabular}{l} 
ARTICLE INFO \\
\hline Article history: \\
Received: 19.1 .2020$. \\
Received in revised form: 16.6 .2020$. \\
Accepted: 26.6 .2020$. \\
\hline Keywords: \\
Straight blade turbine \\
impeller size \\
baffles \\
zeolite mass \\
exchange kinetics \\
\hline DOI: https://doi.org/10.30765/er.1574
\end{tabular}

\section{Introduction}

Zeolites are a large group of natural or synthetic aluminosilicates. Zeolites can be used as catalysts and in separations. For adsorption applications, zeolites are often used for high adsorption capacity for divalent cations. This process seems to be very effective for removal of various heavy metals and adsorbents can be easily recovered and reused by regeneration operation. [1-4] Zeolite $\mathrm{NaX}$ based catalyst can be used in different processes like selective ammonia oxidation, carbon monoxide oxidation at low temperatures, toluene removal, wet peroxide oxidation of phenol, etc. [5-8]. One of the methods of zeolite NaX based catalyst preparation is adsorption. [5-8].

It is known that overall rate in heterogeneous process depends on film diffusion, particle diffusion and reaction. By changing the hydrodynamic conditions and zeolite particle size the slowest step of the process could be defined. Hydrodynamic system conditions are function of impeller characteristics (different impellers generate different fluid flow patterns), i.e. the impeller type and its geometry, the presence or absence of baffles, reactor geometry and characteristics of the solution. [9] Despite the relevance of the

\footnotetext{
* Corresponding author

E-mail address: sanda@ktf-split.hr
}

\begin{abstract}
Effect of hydrodynamics on ion exchange in a batch reactor is still not appropriately studied even though proper mixing parameters may considerably affect the process of solid suspension and its costs. In this work, hydrodynamic conditions suspension in the batch reactor with and without baffles were investigated. The aim of this work was to analyze influence of speed diameter and zeolite mass on just suspended impeller exchanged onto zeolite NaX and copper exchange kinetics as well. All experiments were conducted at the same temperature, size. speed decreases as impeller diameter increases in the reactor with and without baffles but this trend is considerably more pronounced in the reactor with baffles. The increase in zeolite mass causes a slight increase of $N_{J S}$ in the both reactor. In the as impeller diameter decrease. Power consumption, at the state of complete zeolite suspension, decreases as impeller diameter increases and its values in the reactor without baffles are considerably lower as well. Kinetics results indicated that the and then gradually until the equilibrium is reached for all hydrodynamics conditions and mass of zeolite examined.
\end{abstract}


hydrodynamic conditions for adsorption in batch reactor this effect has not received proper attention. Published studies, using batch method, investigate effect of various parameters such as: initial metal concentration, temperature, $\mathrm{pH}$, ionic strength, sorbent dose. In number of studies the effect of mixing was completely neglected and only remark "were shaken" or "the flasks were keeping in a thermostatic orbital shaker" suggest that the mixing was performed. $[10,11]$ In some studies the impeller speed or shaking speed were studied. [12]

The hydrodynamics in reactor affect film diffusion through its effect on film thickness. The simplest way to eliminate film diffusion as the rate controlling step is by applying intensive stirring. Nevertheless, study set in this way, could fail to provide the optimum mixing and cause severe problems. Overmixing may damage solid particles and impeller blades. In addition, there are problems regard to scale up and the costs of the process through the waste of energy. Focus on only stirring intensity and neglecting all other parameters that affect hydrodynamics, as impeller and reactor geometry, also is not the best approach.

The goals of this work were to study the impact of impeller size and zeolite mass in the batch reactor, in the presence and absence of the baffles, on the value of the just suspended impeller speed i.e. the minimum impeller rotational speed necessary for all particles just suspend from the bottom $\left(N_{\mathrm{JS}}\right)$, power consumption per unit mass of suspension $(P / m)$, maximum copper amount exchanged $\left(q_{\mathrm{e}}\right)$ and kinetics. Also, obtained experimental kinetics data were fitted using Blanchard and Weber-Morris model in order to verify that determined $N_{\text {JS }}$ provides conditions in which film diffusion is not the slowest step. Finally, to considering the relationship between amounts of copper exchanged, kinetics and power consumption at the state of complete suspension, proposes the most viable impeller/reactor geometry.

\section{Experimental investigation}

Investigations were carried out in a glass batch reactor (Figure 1) which was equipped with removable four baffles placed at $90^{\circ}$ around the reactor periphery. Reactor diameter, $d_{\mathrm{T}}$, was $0.14 \mathrm{~m}$ and was equal to suspension height, $H$. Standard impeller off-bottom clearance, one-third of the tank diameter, was used. Stirring was performed using a straight blade turbine with four blades (SBT). Impeller size was $6.5 \mathrm{~cm}, 8.0$ $\mathrm{cm}$ and $9.5 \mathrm{~cm}$ (Figure 2). So impeller to tank diameter ratio $\left(D / d_{\mathrm{T}}\right)$ was varied in the range from 0.46 to 0.68 (Figure 2) in the presence and absence of the baffles. The solution containing $\mathrm{Cu}^{2+}$ was prepared by dissolving the appropriate weight of $\mathrm{Cu}\left(\mathrm{NO}_{3}\right)_{2} \cdot 3 \mathrm{H}_{2} \mathrm{O}$ (Kemika). The same volume $\left(2.1 \mathrm{dm}^{3}\right)$ of the solution was used in all experiments. The initial concentration $\left(7.5 \mathrm{mmol} \mathrm{dm}^{-3}\right)$ was checked by Perkin Elmer Lambda 25 UV/VIS spectrophotometer. Zeolite NaX (Sigma Aldrich) with $\mathrm{r}_{\mathrm{Si} / \mathrm{Al}}=1.23$ was crushed and sieved to obtain particles in the range from $0.071-0.090 \mathrm{~mm}$.
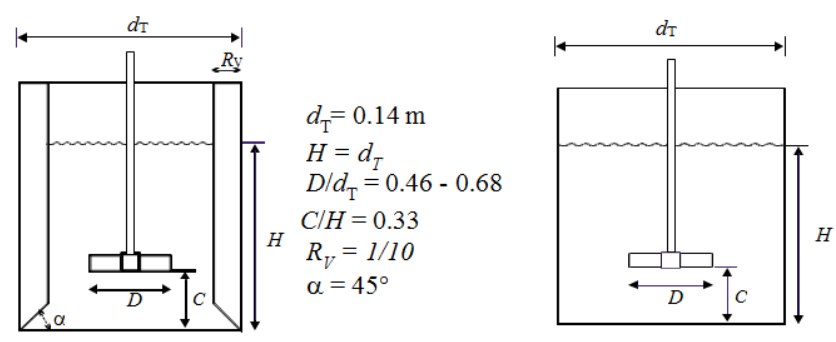

Figure 1. Design details of batch reactor used.

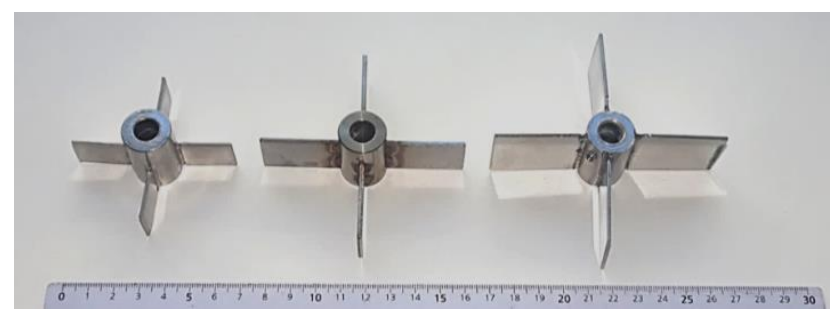

Figure 2. SBT impellers used.

In the first part of the study the critical impeller speed, which ensured the state of the complete suspension of zeolite particles, i.e. just suspended impeller speed, NJS, was determined at different impeller 
diameters and mass of zeolite $(m 1=10.500 \mathrm{~g}, m 2=13.125 \mathrm{~g}, m 3=15.750 \mathrm{~g}$ and $m 4=18.345 \mathrm{~g})$ according to the visual Zwietering criterion. [13] The experiments were conducted in the presence and absence of the baffles. For all examined conditions, power consumption was determined as well. This value represents the energy brought through impellers and it is usually represented as the power consumed per unit mass of suspension $(P / m)$. Power consumption, $P$, was calculated from the values of torque, $\tau$, measured by Lightnin LabMaster LB2.

$$
P=\left(2 \pi \tau N_{\mathrm{JS}}\right)
$$

In the second part of the study, the influence of hydrodynamic conditions on the kinetics of copper exchange was analyzed. All kinetic experiments were carried out at just suspended impeller speed, for all impellers and mass of zeolite used. Solution temperature during the kinetic experiments was kept constant ( $T$ $=300 \mathrm{~K})$. Obtained experimental rate data, were fitted using the two models - Blanchard and Weber-Morris. Blanchard model, reaction-based model, is expressed as: [14]

$$
q_{\mathrm{t}}=\left(q_{\mathrm{e}}^{2} k t\right) /\left(1+q_{\mathrm{e}} k t\right)
$$

where $q_{\mathrm{t}}$ is the amount of copper ions exchanged after time $t(\mathrm{mmol} / \mathrm{g}), q_{\mathrm{e}}$ is the amount of copper ions exchanged at equilibrium - equilibrium capacity $(\mathrm{mmol} / \mathrm{g}), t$ is time $(\mathrm{min})$ and $k$ is the rate constant of the pseudo second order kinetic model ( $\mathrm{g} / \mathrm{mmol} \mathrm{min})$.

The possibility of film or particle diffusion as a rate controlling process was explored by using the WeberMorris model: [15]

$$
q_{\mathrm{t}}=k_{d} t^{1 / 2}+I
$$

where $k_{\mathrm{d}}$ is the intraparticle diffusion rate constant $\left(\mathrm{mmol} / \mathrm{g} \min ^{1 / 2}\right), t$ is time (min) and $I$ is the intercept of the vertical axis. If the Weber-Morris plot of $q_{\mathrm{t}}$ versus $\mathrm{t}^{1 / 2}$ gives a straight line through the origin, $I=0$, intraparticle diffusion is considered as the rate-limiting step, while, at $I>0$ both film and intraparticle diffusion are considered as rate-limiting steps. [16]

\section{Results and discussion}

\subsection{Hydrodynamics}

In the two-phase reactor (liquid-solid) mixing needs to ensure suspension of solid particles and appropriate conditions for effective film diffusion.

In this study, all experiments were carried out at just suspended impeller speed, according to the visual Zwietering criterion meaning that all particles are in motion and no particle remains on the reactor bottom for more than 1 or $2 \mathrm{sec}$. [13] Figure 3 shows the effect of impeller size and zeolite mass on value of $N_{\mathrm{JS}}$ in the presence and absence of baffles. As it is shown in Figure $3 N_{\mathrm{JS}}$ decreases as impeller diameter increases in the reactor with and without baffles but the $N_{\mathrm{JS}}$ is considerably lower in the reactor without baffles.

Influence of impeller diameter on just suspended impeller speed could be understood analyzing the fluid flow pattern that SBT impeller produces. When SBT impeller is used than radial flow inside the reactor is generated if the impeller is set to standard impeller off-bottom clearance. Radial flow means that suspension is discharged from the impeller in the radial direction towards the reactor walls where it splits into two loops. One is directed towards the reactor bottom and the other towards the surface. [17] The lower circulation loop is responsible for the suspension of zeolite particles settled at the bottom of the reactor. Namely, by rotating the impeller first large eddies are produced and then cascade process is taking place (Kolomogorov scale).

In order to suspend the settled zeolite particles from the bottom, the size of eddy near the bottom must be large enough to lift them and incorporate into the liquid phase. The critical eddies responsible for just suspend the particle by large impeller is crated at lower impeller rotational speed. In the reactor equipped with the baffles the increase in zeolite mass causes a slight increase of $N_{\mathrm{JS}}$ which is more pronounced in the systems with smaller impeller. In the reactor without baffles the increase in zeolite mass also causes the slight but uniform increase of $N_{\mathrm{JS}}$ at all impeller diameters used. 
In unbaffled reactor at $N_{\mathrm{JS}}$, for all impellers used, the suspension is rotating in big circle which does not allow settling of the zeolite particles on the bottom but at the same time does not provide the top-to-bottom suspension circulation.

Mixing performed at $N_{\mathrm{JS}}$ reflects on the values of power consumption (Figure 4). As can be seen from the Eq. (1) power consumption is proportional to the $N_{\text {JS. }}$. Lower just suspended impeller speed resulted in lower $P / m$. Power consumption increases with zeolite mass but the influence of zeolite mass on this parameter is considerably lower than the influence of impeller speed. Significantly, higher power consumption in a baffled system could be attributed to, not only higher $N_{\text {IS }}$ but also to the higher resistance force which baffles exert to the tangential fluid flow. Finally, power consumption is lowest for the largest impeller $\left(D / d_{\mathrm{T}}=0.68\right)$ and the smallest mass of zeolite used $(m 1=10.500 \mathrm{~g})$ in the reactor with and without baffles. In the unbaffled system, this effect is even more pronounced.
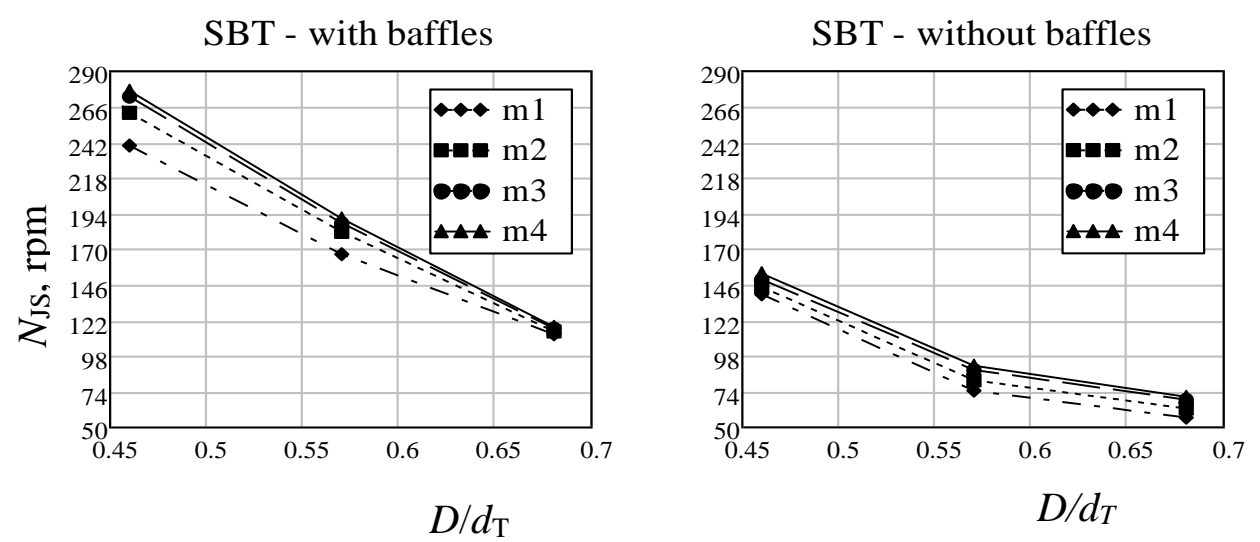

Figure 3. Effect of $D / d_{T}$ ratio and mass of zeolite on the minimum impeller speed, $N_{\mathrm{JS}}$.
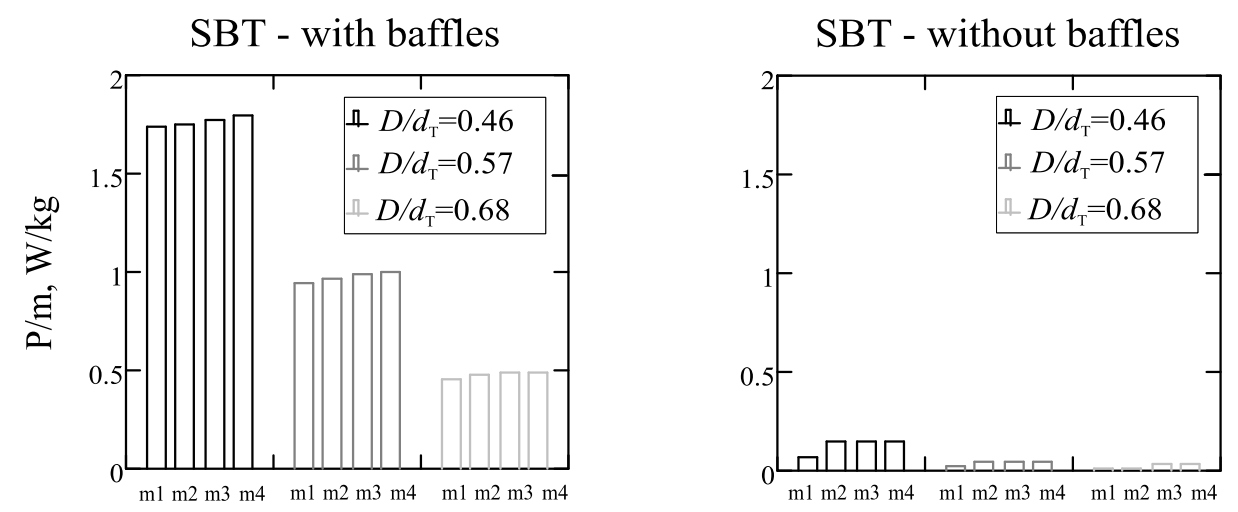

Figure 4. Effect of impeller size and mass of zeolite on power consumption per unit mass of suspension.

\subsection{Kinetics}

The effect of parameters investigated (zeolite mass, impeller size and presence of baffles at $N_{\mathrm{JS}}$,) on copper exchange kinetics are shown in Figure 5. The shape of the curves in Figure 5 indicates that amount of copper ion exchanged sharply increases with the time in the first few minutes (length of this stage depends on zeolite mass) and then increases gradually until the equilibrium is reached. From the results is also clear that zeolite mass has more effect on $q_{\mathrm{e}}$ than hydrodynamic conditions generated at applied $D / d_{\mathrm{T}}$ ratio; $q_{\mathrm{e}}$ decreases with zeolite mass decrement regardless of SBT impeller size and baffles presence. 

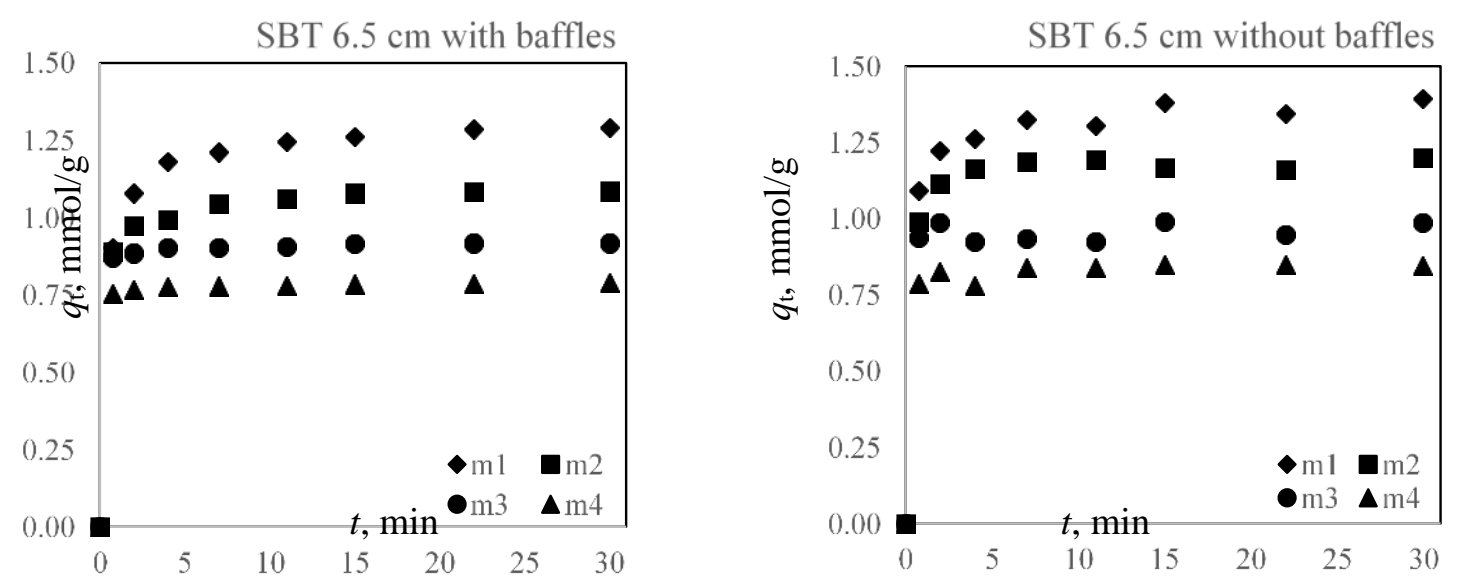

SBT $8.0 \mathrm{~cm}$ with baffles

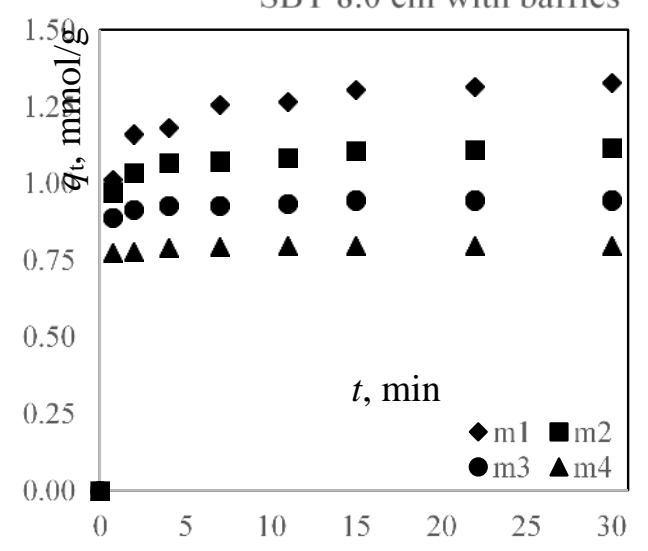

SBT $8.0 \mathrm{~cm}$ without baffles
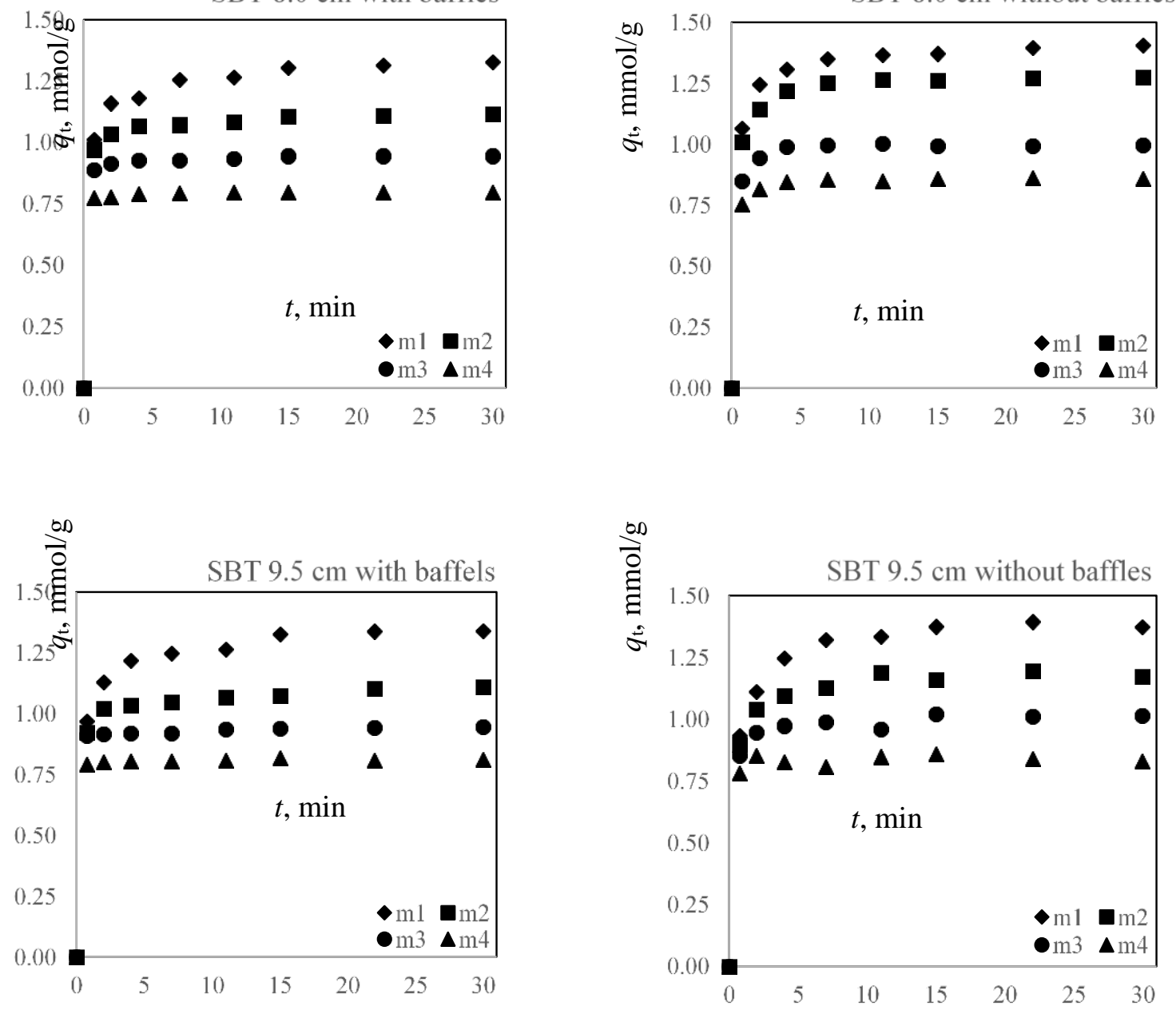

Figure 5. Experimental kinetic data. 


\begin{tabular}{|c|c|c|c|c|c|c|c|c|}
\hline \multirow{4}{*}{ 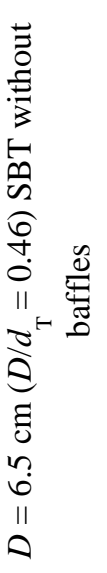 } & $\stackrel{\mathbb{N}}{\Xi}$ & $\begin{array}{l}\mathfrak{n} \\
\infty \\
0 \\
0\end{array}$ & $\begin{array}{l}+ \\
\stackrel{+}{0} \\
0\end{array}$ & 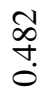 & तु. & $\begin{array}{l}\hat{\tilde{\alpha}} \\
\overrightarrow{\tilde{N}}\end{array}$ & $\begin{array}{l}\vec{F} \\
\stackrel{\infty}{0} \\
0\end{array}$ & $\stackrel{\varrho}{\circ}$ \\
\hline & $\cong$ & $\begin{array}{l}\infty \\
\infty \\
\vdots \\
0\end{array}$ & $\frac{\infty}{0}$ & 先 & 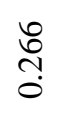 & 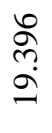 & ڤે & 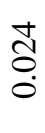 \\
\hline & $\cong$ & 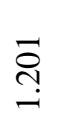 & $\stackrel{\text { ले }}{\stackrel{0}{0}}$ & 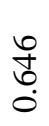 & $\frac{0}{m}$ & $\begin{array}{l}\bar{\infty} \\
\stackrel{+}{+} \\
\text { in }\end{array}$ & $\stackrel{\infty}{\stackrel{\varrho}{\rightleftarrows}}$ & $\begin{array}{l}0 \\
\stackrel{0}{0} \\
0\end{array}$ \\
\hline & ミ & $\stackrel{\text { }}{\dddot{m}}$ & $\frac{?}{0}$ & $\begin{array}{l}8 \\
\text { ô. } \\
0\end{array}$ & $\stackrel{n}{m}$ & 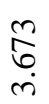 & 节 & 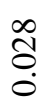 \\
\hline \multirow{4}{*}{ 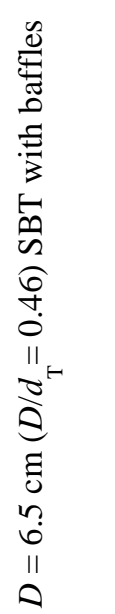 } & $\stackrel{\mathbb{Z}}{\Xi}$ & $\begin{array}{l}\text { f } \\
\infty \\
0 \\
0\end{array}$ & $\begin{array}{l}\mathscr{\delta} \\
0\end{array}$ & 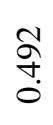 & $\stackrel{\infty}{\underset{n}{0}}$ & $\begin{array}{l}\text { Uू } \\
\text { ì } \\
\text { ה }\end{array}$ & $\begin{array}{l}0 \\
\infty \\
\infty \\
0 \\
0\end{array}$ & $\begin{array}{l}\widetilde{\delta} \\
\stackrel{0}{0}\end{array}$ \\
\hline & $\stackrel{2}{I}$ & 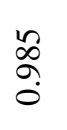 & $\stackrel{\infty}{\stackrel{\infty}{0}}$ & $\begin{array}{l}\infty \\
\hat{n} \\
0\end{array}$ & 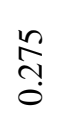 & $\stackrel{\infty}{=}$ & 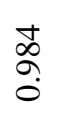 & $\underset{0}{\stackrel{t}{0}}$ \\
\hline & $\cong$ & $\stackrel{\Xi}{\rightrightarrows}$ & $\frac{0}{1}$ & $\begin{array}{l}\bar{\sigma} \\
0 \\
0\end{array}$ & 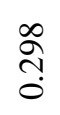 & 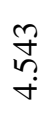 & $\stackrel{\infty}{=}$ & $\frac{\sigma}{0}$ \\
\hline & ミ & ભે & $\frac{\vec{\infty}}{\overrightarrow{0}}$ & $\begin{array}{l}\tilde{n} \\
\text { b. } \\
0\end{array}$ & $\begin{array}{c}\tilde{n} \\
\tilde{0} \\
\tilde{0}\end{array}$ & $\begin{array}{l}\stackrel{2}{\sim} \\
\text { in }\end{array}$ & $\begin{array}{l}\stackrel{2}{\infty} \\
\text { m. }\end{array}$ & $\begin{array}{l}\stackrel{0}{\circ} \\
\stackrel{0}{0}\end{array}$ \\
\hline \multicolumn{2}{|l|}{ 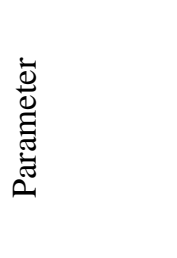 } & 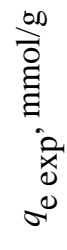 & 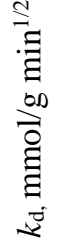 & 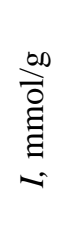 & $\sum_{\underline{\alpha}}^{5}$ & 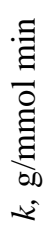 & 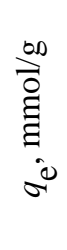 & $\sum_{\Omega}^{5}$ \\
\hline $\begin{array}{l}\frac{\bar{\theta}}{\overline{0}} \\
\sum\end{array}$ & & 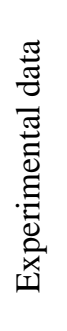 & \multicolumn{3}{|l|}{ 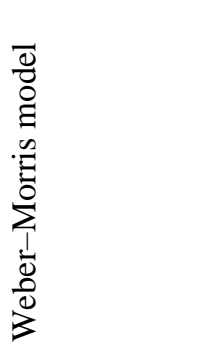 } & \multicolumn{3}{|l|}{ 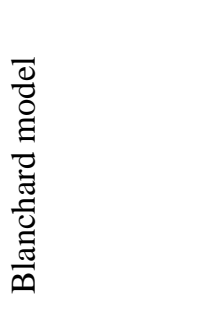 } \\
\hline
\end{tabular}




\begin{tabular}{|c|c|c|c|c|c|c|c|c|}
\hline \multirow{4}{*}{ 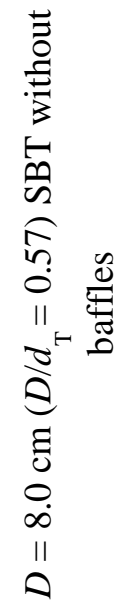 } & $\stackrel{\mathbb{Z}}{\Xi}$ & $\begin{array}{l}8 \\
\stackrel{0}{0} \\
\stackrel{0}{0}\end{array}$ & $\stackrel{2}{\circ}$ & 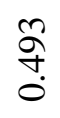 & 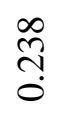 & $\begin{array}{l}\text { No } \\
\infty \\
\infty\end{array}$ & $\begin{array}{l}\hat{\sigma} \\
\infty \\
0 \\
0\end{array}$ & $\stackrel{\infty}{8}$ \\
\hline & $\stackrel{2}{\cong}$ & ڤ̆ & $\stackrel{n}{=}$ & $\begin{array}{l}n \\
n \\
n\end{array}$ & 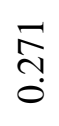 & $\stackrel{\overbrace{}}{\stackrel{n}{r}}$ & $\stackrel{\Xi}{\underline{0}}$ & $\begin{array}{l}\text { gి } \\
\text { ㅇ }\end{array}$ \\
\hline & $\cong$ & 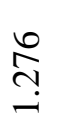 & $\frac{n}{0}$ & $\begin{array}{l}n \\
\tilde{b} \\
0\end{array}$ & तె & $\begin{array}{l}\stackrel{D}{\infty} \\
\stackrel{\leftrightarrow}{0} \\
\text { r. }\end{array}$ & $\begin{array}{l}\stackrel{+}{\infty} \\
\stackrel{1}{\longrightarrow}\end{array}$ & $\stackrel{\infty}{8}$ \\
\hline & ミ & $\stackrel{\text { }}{\stackrel{\leftrightarrow}{+}}$ & 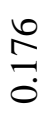 & 苛 & $\stackrel{\vec{f}}{\text { ?े }}$ & $\begin{array}{l}\vec{\sigma} \\
\vec{i}\end{array}$ & ָ̊ & $\begin{array}{l}0 \\
0 \\
0\end{array}$ \\
\hline \multirow{4}{*}{ 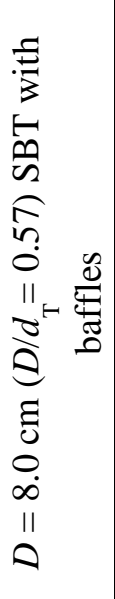 } & $\stackrel{\mathbb{Z}}{\Xi}$ & $\begin{array}{l}\mathscr{L} \\
\infty \\
0 \\
0\end{array}$ & $\stackrel{\Omega}{0}$ & $\begin{array}{l}\text { ô } \\
\text { n̊ }\end{array}$ & 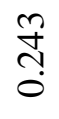 & $\begin{array}{l}\text { o } \\
+ \\
\text { ì }\end{array}$ & $\begin{array}{l}\tilde{n} \\
\infty \\
0 \\
0\end{array}$ & 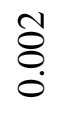 \\
\hline & $\stackrel{2}{\equiv}$ & $\begin{array}{l}\infty \\
\stackrel{\Omega}{\sigma} \\
0\end{array}$ & $\begin{array}{l}\stackrel{8}{0} \\
\stackrel{0}{0}\end{array}$ & in & 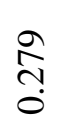 & $\begin{array}{l}\infty \\
\infty \\
\stackrel{?}{=} \\
=\end{array}$ & $\hat{a}$ & $\begin{array}{l}\text { D } \\
\\
0\end{array}$ \\
\hline & $\cong$ & $\stackrel{\text { }}{\underset{\sim}{N}}$ & $\frac{ \pm}{\stackrel{ \pm}{0}}$ & \begin{tabular}{l}
\multirow{6}{6}{} \\
0 \\
0
\end{tabular} & $\frac{a}{3}$ & 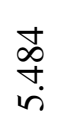 & 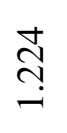 & $\stackrel{8}{0}$ \\
\hline & ミ & 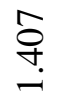 & $\stackrel{\vec{\infty}}{\overrightarrow{0}}$ & $\begin{array}{l}0 \\
0 \\
0 \\
0\end{array}$ & ते & $\underset{i}{\stackrel{O}{f}}$ & ஓ. & $\begin{array}{l}\overrightarrow{\widehat{O}} \\
\stackrel{0}{0}\end{array}$ \\
\hline \multicolumn{2}{|l|}{$\begin{array}{l}\overline{\bar{\Xi}} \\
\stackrel{\Xi}{\Xi} \\
\bar{\Xi} \\
\tilde{\Xi}\end{array}$} & 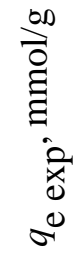 & 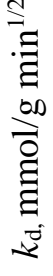 & 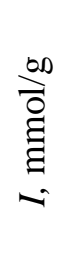 & $\sum_{\underline{\Omega}}^{\sqrt[W]{\mathscr{N}}}$ & 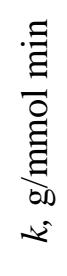 & $\begin{array}{l}\frac{000}{\overrightarrow{0}} \\
\stackrel{0}{0} \\
\hat{0} \\
\text { of }\end{array}$ & $\sum_{\Omega}^{\sqrt[N]{\Omega}}$ \\
\hline $\begin{array}{l}\bar{\theta} \\
\frac{\delta}{\Sigma}\end{array}$ & & 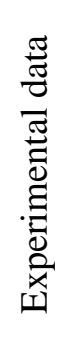 & 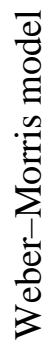 & & & \multicolumn{3}{|l|}{ 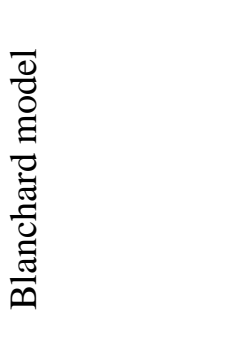 } \\
\hline
\end{tabular}




\begin{tabular}{|c|c|c|c|c|c|c|c|c|}
\hline \multirow{4}{*}{ 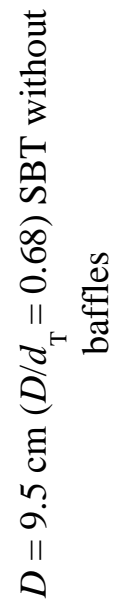 } & $\stackrel{\mathbb{Z}}{\Xi}$ & $\begin{array}{l}\overline{\tilde{\infty}} \\
\stackrel{0}{0}\end{array}$ & $\stackrel{\text { ô }}{\circ}$ & 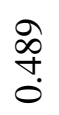 & $\stackrel{\hat{\vartheta}}{\hat{\sigma}}$ & 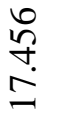 & $\begin{array}{l}\text { fे } \\
\infty \\
0\end{array}$ & $\stackrel{\hat{n}}{\hat{0}}$ \\
\hline & $\geqq$ & $\stackrel{n}{\sigma}$ & $\stackrel{a}{\overrightarrow{0}}$ & $\stackrel{m}{n}$ & $\begin{array}{l}\text { do } \\
\text { ֶ̦ }\end{array}$ & $\stackrel{\Omega}{\check{\sigma}}$ & $\stackrel{\circ}{0}$ & $\stackrel{\Gamma}{\circ}$ \\
\hline & $\cong$ & $\Xi$ & 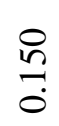 & $\begin{array}{l}\bar{\infty} \\
\stackrel{n}{0} \\
0\end{array}$ & $\begin{array}{l}\stackrel{0}{\infty} \\
\stackrel{1}{0} \\
0\end{array}$ & ले & $\begin{array}{l}\mathscr{\infty} \\
= \\
=\end{array}$ & 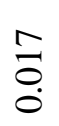 \\
\hline & ミ & 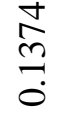 & $\frac{\infty}{\stackrel{\infty}{0}}$ & $\begin{array}{l}\bar{\sigma} \\
\dot{0}\end{array}$ & ڤ్రి & $\underset{⿱}{\stackrel{J}{ \pm}}$ & $\begin{array}{l}\check{2} \\
\text { mे }\end{array}$ & $\stackrel{r}{\circ}$ \\
\hline \multirow{4}{*}{ 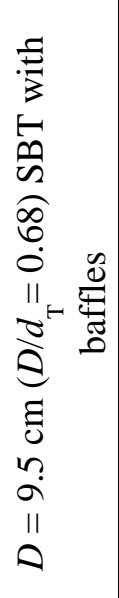 } & $\stackrel{\mathbb{Z}}{\Xi}$ & $\begin{array}{l}\widetilde{n} \\
\infty \\
0 \\
0\end{array}$ & $\stackrel{\mathscr{\alpha}}{\stackrel{0}{0}}$ & $\stackrel{\text { ঃ̊ }}{\stackrel{+}{0}}$ & $\stackrel{\stackrel{?}{+}}{\stackrel{0}{0}}$ & $\begin{array}{l}\stackrel{a}{+} \\
\stackrel{+}{\&}\end{array}$ & $\begin{array}{l}\tilde{\omega} \\
\infty \\
0 \\
0\end{array}$ & 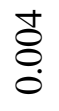 \\
\hline & ミ & ڤे & $\frac{8}{0}$ & 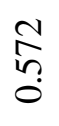 & 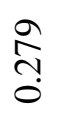 & $\begin{array}{l}\text { के } \\
\text { ळे } \\
\text { ते }\end{array}$ & $\begin{array}{l}+ \\
\stackrel{\circ}{\sigma}\end{array}$ & $\stackrel{5}{0}$ \\
\hline & ミ & $\begin{array}{l}\stackrel{\infty}{\infty} \\
\rightleftharpoons\end{array}$ & $\frac{\infty}{\sim}$ & 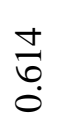 & 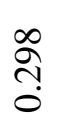 & $\begin{array}{l}\hat{\sigma} \\
\hat{n}\end{array}$ & $\stackrel{n}{=}$ & $\stackrel{r}{0}$ \\
\hline & $\Xi$ & $\begin{array}{l}\bar{\infty} \\
\stackrel{n}{n}\end{array}$ & $\frac{2}{0}$ & $\begin{array}{l}\underbrace{0}_{0} \\
\text {. } \\
0\end{array}$ & $\frac{n}{n}$ & $\frac{\Delta}{\vec{n}}$ & $\stackrel{?}{\stackrel{?}{?}}$ & 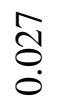 \\
\hline \multicolumn{2}{|l|}{ 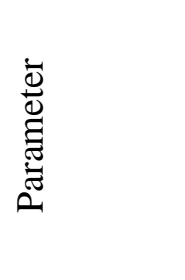 } & $\begin{array}{l}\text { on } \\
\overrightarrow{0} \\
\vdots \\
\vdots \\
0 \\
0 \\
0 \\
0\end{array}$ & 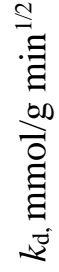 & 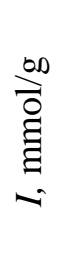 & $\sum_{\underline{\underline{N}}}^{\sqrt[T]{\mathscr{N}}}$ & 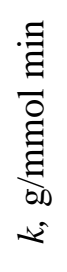 & 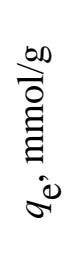 & $\sum_{\Omega 1}^{\mathbb{N}}$ \\
\hline \multicolumn{2}{|l|}{$\begin{array}{l}\bar{d} \\
\frac{\bar{d}}{0} \\
\sum\end{array}$} & 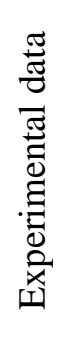 & \multicolumn{3}{|l|}{ 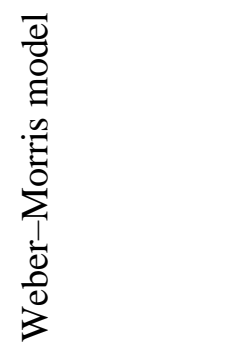 } & \multicolumn{3}{|l|}{ 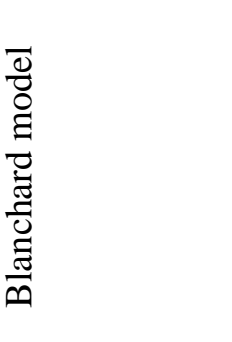 } \\
\hline
\end{tabular}



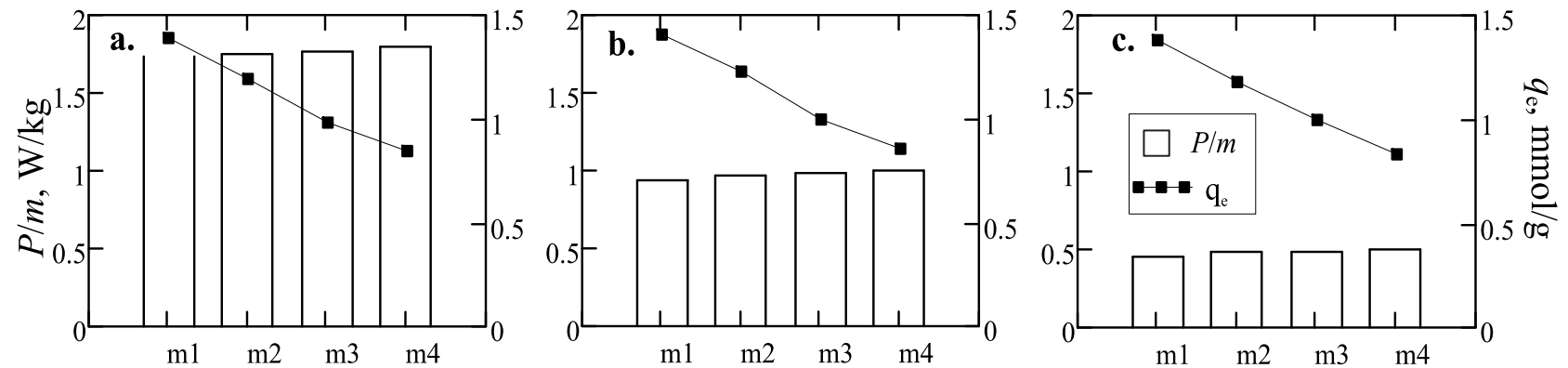

Figure 6. Relationship between amount of copper exchanged and power consumption per unit mass of suspension at different masses of zeolite in the reactor with baffles and with SBT impeller of diameter a) $D=6.5 \mathrm{~cm}\left(D / d_{T}=0.46\right) \quad$ b) $D=8.0 \mathrm{~cm}\left(D / d_{T}=0.57\right) \quad$ c) $D=9.5 \mathrm{~cm}\left(D / d_{T}=\right.$

$0.68)$.

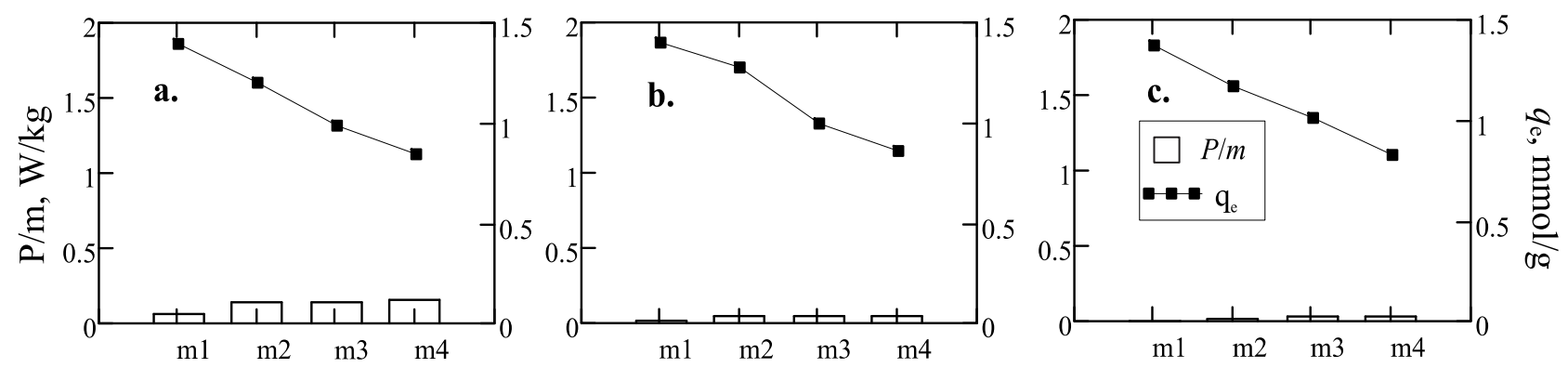

Figure 7. Relationship between amount of copper exchanged and power consumption per unit mass of suspension at different masses of zeolite in the reactor without baffles and with SBT impeller of diameter a) $D=6.5 \mathrm{~cm}\left(D / d_{T}=0.46\right) \quad$ b) $D=8.0 \mathrm{~cm}\left(D / d_{T}=0.57\right) \quad$ c) $D=9.5 \mathrm{~cm}\left(D / d_{T}=\right.$

$0.68)$.

However, in order to make more precise results' analysis, the kinetic experimental results were fitted to the kinetic models presented above. Models parameters were calculated using non-linear (Blanchard model) and linear (Weber-Morris model) least square method, using Mathcad, and are given in the Table 1. The reaction, second order, was found to limit the overall reaction rate. For the smallest impeller used the rate constant determined by Blanchard model is higher in reactor without baffles at all zeolite masses except the highest one. On the contrary, for larger impellers higher rate constants are calculated for kinetic experiments conducted in the baffled reactor.

From the values of $q_{\mathrm{e}}$ and the rate constants given in the Table 1 can be seen that at lower zeolite masses ( $m 1$ and $m 2$ ) influence of impeller diameter on exchange in baffled reactor might be considered negligible. For $m 3$ the difference is observed for the largest impeller used, and for $m 4$ the rate constant noticeable differs for all impeller size used. When baffles were positioned in the reactor the increase in impeller size positively affect the exchange rate. Namely, larger impeller causes higher exchange rate due to more pronounces radial flow in the impeller zone. Impeller capture particles from the surface, faster draw them into the solution and shorten time needed for its suspension. On the other hand, in unbaffled system experiments, an increase of impeller size does not have a pronounced effect on fluid flow pattern which is characterized by swirling motion. Here, flow pattern remained unchanged but due to lower $N_{\mathrm{JS}}$ and fluid velocity homogenization of suspension is slower and consequently he rate constants decrease with impeller size.

Unlike the just suspended impeller speed and power consumption, amount of copper adsorbed does not depend, significantly, on impeller size (Figure 6,7) and it, as expected, decreases with an increase of zeolite mass. However, as can be seen in Figures 6 and 7, although $q_{\mathrm{e}}$ doesn't significantly change due to impeller size and presence or absence of baffles, the power consumption does. This parameter and values of rate constants enable selection of optimal hydrodynamics parameters for the system investigated. In this work impeller ratio $D / d_{\mathrm{T}}=0.68$ could be considered the most viable ratio of SBT impeller from the view point of energy costs, especially in the unbaffled system. On the other hand, at this impeller diameter ratio the 
adsorption rate is the slowest for unbaffled reactor, while for the baffled one represents also the most viable value.

\section{Conclusion}

The following conclusions from the results of the studies, of the influence of SBT impeller size and mass of zeolite in the absence and presence of baffles in the reactor, may be drawn:

- $N_{\mathrm{JS}}$ value significantly decreases with impeller size but slightly increases with a mass concentration of zeolite

- Power consumption per unit mass of suspension decreases by increasing impeller diameter and by removing baffles. This parameter slightly increases with a mass concentration of zeolite in the baffled and unbaffled systems

- The ion exchange capacity isn't significantly affected by impeller size but is, unfavorably, by mass of zeolite

- The experimental kinetics data can be fitted with Weber-Morris and Blanchard model

- Blanchard model is better in describing the exchange of copper on zeolite $\mathrm{NaX}$ indicating that reaction is rate-controlling step in all kinetic experiments

- The most viable hydrodynamic conditions regarding power consumption are obtained applying impeller with diameter to tank ratio of 0.68 .

\section{References}

[1] Gunatilake, S. K.: Methods of Removing Heavy Metals from Industrial Wastewater, Journal of Multidisciplinary Engineering Science Studies 1 (2015), 1, 12-18

[2] Yilmaz, B., Müller, U.: Catalytic Applications of Zeolites in Chemical Industry, Topics in Catalysis, 52 (2009), 6-7, 888-895.

[3] Akhtar, F., Andersson, L., Ogunwumi, S., Hedin, N., Bergström, L.: Structuring adsorbents and catalysts by processing of porous powders, Journal of the European Ceramic Society, 34 (2014) 7, 1643-1666.

[4] Ji, X. D., Ma, Y. Y., Peng, S. H., Gong, Y. Y., Zhang, F.: Simultaneous removal of aqueous Zn2+, $\mathrm{Cu} 2+, \mathrm{Cd} 2+$ and $\mathrm{Pb2}+$ by zeolites synthesized from low-calcium and high-calcium fly ash, Water Science \& Technology, 76 (2017), 7-8, 2106-2119.

[5] Jabłońska. M., Palkovits, R.: Copper based catalysts for the selective ammonia oxidation into nitrogen and water vapor - Recent trends and open challenges, Applied Catalysis B Environmental, 181 (2016), 332-351,

[6] Tkachenko, O. P., Greish, A. A., Kucherov, A. V., Weston K. C., Tsybulevski, A. M., Kustov L. M.: Low-temperature $C O$ oxidation by transition metal polycation exchanged low-silica faujasites, Applied Catalysis B Environmental, 179 (2015), 521-529.

[7] Romero, D., Chlala, D., Labaki, M., Royer S., Bellat J-P., Bezverkhyy I., Giraudon J-M., Lamonier J-F.: Removal of Toluene over NaX Zeolite Exchanged with $\mathrm{Cu}^{2+}$, Catalysis 5 (2015), 1479-1497.

[8] Maduna Valkaj, K., Katović, A., Zrnčević, S.: Catalytic Properties of Cu/13X Zeolite Based Catalyst in Catalytic Wet Peroxide Oxidation of Phenol, Industrial \& Engineering Chemistry Research 50 (2011), 8, 4390-4397.

[9] Stoian, D.: Enhancing energy efficiency and mass transfer in solid-liquid systems using mechanical mixing and cavitation, School of Engineering, College of Science Engineering and Health, RMIT University, Melbourne (Doctoral dissertation) 2017.

[10] Liu, X., Chen, Z-Q., Han, B., Su, C-L., Han, Q., Chen, W-Z.: Biosorption of copper ions from aqueous solutions using rape straw powders: Optimization, equilibrium and kinetic study, Ecotoxicology and Environmental Safety 150 (2018), 251-259.

[11] Cao, W., Wang, Z., Ao, H., Yuan, B.: Removal of Cr(VI) by corn stalk based anion exchanger the extent and rate of $\mathrm{Cr}(\mathrm{VI})$ reduction as side reaction, Colloids and Surfaces A, 539 (2018), 424-432.

[12] Inglezakis, V. J., Diamandis, N. A., Loizidou, M. D., Grigoropoulou, H. P.: Effect of pore clogging on kinetics of lead uptake by clinoptilolite, Journal of Colloid and Interface Science 215 (1999), 1, 54-57.

[13] Zweietering, T. N.: Suspending of solid particles in liquid by agitators, Chemical Engineering Science, 8 (1958), 224-253 
[14] Blanchard, G., Maunaye, M., Martin, M.: Removal of heavy metals from waters by means of natural zeolites, Water Research. 18 (1984), 12, 1501-1507.

[15] Weber, W. J. Morris, J. C.: Kinetics of adsorption on carbon from solution, Journal of Sanitary Engineering Division, Proceedings of the American Society of Civil Engineers, SA2 (1963), 2, 31-60.

[16] Svilović, S., Rušić, D., Stipišić, R.: Modeling batch kinetics of copper ions sorption using synthetic zeolite NaX, Journal of Hazardous Materials, 170 (2009), 2-3, 941-947.

[17] Svilović, S., Horvat, I., Ćosić, M., Stipišić, R.: Investigation on the effects of process variables on copper exchange on $\mathrm{NaX}$ in batch stirred reactor, Tehnički glasnik - Tehnical Journal, 11 (2017), 4, 7174. 